\title{
A Comparative Study on Phytochemical Profiles and Biological Activities of Sclerocarya birrea (A.Rich.) Hochst Leaf and Bark Extracts
}

\author{
Daniela Russo ${ }^{1,+}{ }^{,}$, Rocchina Miglionico ${ }^{1,+}{ }^{\dagger}$, Monica Carmosino ${ }^{1}$, Faustino Bisaccia ${ }^{1}$, \\ Paula B. Andrade 2 (D), Patrícia Valentão ${ }^{2}$ (D), Luigi Milella ${ }^{1, *}$ \\ and Maria Francesca Armentano ${ }^{1}$ \\ 1 University of Basilicata, Department of Science, V.le dell'AteneoLucano, 85100 Potenza, Italy; \\ daniela.russo@unibas.it (D.R.); rocchina.miglionico@virgilio.it (R.M.); monica.carmosino@unibas.it (M.C.); \\ faustino.bisaccia@unibas.it (F.B.); mariafrancesca.armentano@unibas.it (M.F.A.) \\ 2 REQUIMTE/LAQV, Laboratório de Farmacognosia, Departamento de Química, Faculdade de Farmácia, \\ Universidade do Porto, R. Jorge Viterbo Ferreira, nº 228, 4050-313 Porto, Portugal; \\ pandrade@ff.up.pt (P.B.A.); valentao@ff.up.pt (P.V.) \\ * Correspondence: luigi.milella@unibas.it; Tel.: +39-0971-205-525; Fax: +39-0971-205-501 \\ $\dagger$ These authors contributed equally to this work.
}

Received: 16 December 2017; Accepted: 2 January 2018; Published: 8 January 2018

\begin{abstract}
Sclerocarya birrea (A.Rich.) Hochst (Anacardiaceae) is a savannah tree that has long been used in sub-Saharan Africa as a medicinal remedy for numerous ailments. The purpose of this study was to increase the scientific knowledge about this plant by evaluating the total content of polyphenols, flavonoids, and tannins in the methanol extracts of the leaves and bark (MLE and MBE, respectively), as well as the in vitro antioxidant activity and biological activities of these extracts. Reported results show that MLE is rich in flavonoids (132.7 $\pm 10.4 \mathrm{mg}$ of quercetin equivalents $/ \mathrm{g}$ ), whereas MBE has the highest content of tannins (949.5 $\pm 29.7 \mathrm{mg}$ of tannic acid equivalents/g). The antioxidant activity was measured using four different in vitro tests: $\beta$-carotene bleaching (BCB), 2,2'-azino-bis(3-ethylbenzothiazoline-6-sulfonic acid) (ABTS), $\mathrm{O}_{2}{ }^{-}{ }^{\bullet}$, and nitric oxide (NO ${ }^{\bullet}$ ) assays. In all cases, MBE was the most active compared to MLE and the standards used (Trolox and ascorbic acid). Furthermore, MBE and MLE were tested to evaluate their activity in HepG2 and fibroblast cell lines. A higher cytotoxic activity of MBE was evidenced and confirmed by more pronounced alterations in cell morphology. MBE induced cell death, triggering the intrinsic apoptotic pathway by reactive oxygen species (ROS) generation, which led to a loss of mitochondrial membrane potential with subsequent cytochrome $c$ release from the mitochondria into the cytosol. Moreover, MBE showed lower cytotoxicity in normal human dermal fibroblasts, suggesting its potential as a selective anticancer agent.
\end{abstract}

Keywords: polyphenols; cytotoxic effect; ROS; apoptosis; mitochondrial membrane potential; HepG2 cell line

\section{Introduction}

Plants are considered to be producers of natural compounds that have been used by humans in medicines to treat diseases since ancient times. Nowadays, a large number of drugs used against various diseases have been isolated or derived from natural sources, often starting from their use in traditional medicine [1].

The biological activities from natural sources are due to the variety of chemicals that are widely distributed in nature [2-5]. In particular, several studies have attributed important bioactivities to polyphenols, which include anti-inflammatory, analgesic, antimicrobial, and apoptosis-inducing 
properties, and the possible use of these compounds as anticancer drugs [6,7]. It has been previously demonstrated that polyphenols can act as both antioxidants and pro-oxidants, depending on their concentration and the cellular environment [8].

Sclerocarya birrea (A.Rich.) Hochst (Anacardiaceae), commonly known as marula, has long been used in sub-Saharan Africa as a medicinal remedy for numerous ailments: indeed, the stem bark, roots, and leaves of S. birrea are used to treat hypertension, diabetes, dysentery, and inflammation [9].

It has been reported that extracts from S. birrea roots inhibit the growth of Candida spp. and Cryptococcus neoformans [10]; the root extract also possesses important in vitro antioxidant activity with particular regard to its free radical scavenging activity, and exhibits cytotoxic effects linked to increasing amounts of reactive oxygen species (ROS) in HepG2 cells [11,12]. Moreover, water and acetone extracts of stem bark show anticancer and proapoptotic activities [13]. Previous studies [14-16] investigated the phytochemical profile of different parts of S. birrea and it was found that polyphenols, including phenolic acid, flavonoids and their glycosides and procyanidins, were the main compounds. Considering the antioxidant and proapoptotic activity of the methanol extract of $S$. birrea root [12] and in order to clarify the biological activity of different parts of this plant, the aim of this study was to investigate the in vitro antioxidant properties and the cytotoxic activity of leaf and bark methanol extracts in a carcinoma cell line (HepG2). To the best of our knowledge, this is the first study that has evaluated and compared the cytotoxic activities of S. birrea bark and leaf extracts on the human hepatocarcinoma cell line (HepG2) vs. fibroblasts.

\section{Results}

\subsection{Total Polyphenol (TPC), Flavonoid (TFC), and Tannin Content (TTC) Evaluation}

Table 1 shows the total polyphenol content (TPC) of the extracts measured using the Folin-Ciocalteu reagent; the values are expressed as milligram $(\mathrm{mg})$ of gallic acid equivalents $(\mathrm{GAE})$ per gram $(\mathrm{g})$ of dried extract. The TPC values of the $S$. birrea leaf extracts ranged from $30.2 \pm 1.3 \mathrm{mg} \mathrm{GAE} / \mathrm{g}$ ( $n$-hexane leaf extract, HLE) to $62.6 \pm 0.8 \mathrm{mg} \mathrm{GAE} / \mathrm{g}$ (methanol leaf extract, MLE), whereas the TPC values of the bark extracts ranged from $31.3 \pm 0.2 \mathrm{mg} \mathrm{GAE} / \mathrm{g}$ (chloroform:methanol bark extract, CMBE) to $241.3 \pm 8.9 \mathrm{mg}$ GAE/g (methanol bark extract, MBE). The tannin content of the leaf and bark extracts are expressed as milligram (mg) of tannic acid equivalents (TAE) per gram (g) of dried extract and ranged from $74.2 \pm 5.5 \mathrm{mg}$ TAE/g (chloroform:methanol leaf extract, CMLE) to $175.8 \pm 5.5 \mathrm{mg}$ TAE/g (CLE) in S. birrea leaves and from $158.7 \pm 1.6 \mathrm{mg}$ TAE/g (CMBE) to $949.5 \pm 29.7 \mathrm{mg}$ TAE$/ \mathrm{g}$ (MBE) in bark extracts. The highest TFC (mg of quercetin equivalents (QE) per g) was observed in MLE (132.7 $\pm 10.4 \mathrm{mg}$ QE/g of dried extract) and MBE $(57.7 \pm 3.5 \mathrm{mg}$ QE/g of dried extract), whereas the lowest values were observed in $n$-hexane extracts $(8.3 \pm 1.2 \mathrm{mg} \mathrm{TAE} / \mathrm{g}$ in HLE and $4.7 \pm 0.5 \mathrm{mg}$ TAE/g in $n$-hexane bark extract (HBE)) (Table 1).

Table 1. Total polyphenol content (TPC), total tannin content (TTC), and total flavonoid content (TFC) in leaf and bark extracts of S. birrea.

\begin{tabular}{cccc}
\hline & TPC $(\mathbf{m g}$ GAE/g) & TTC $(\mathbf{m g}$ TAE/g) & TFC $(\mathbf{m g}$ QE/g) \\
\hline HLE & $30.2 \pm 1.3$ & $102.4 \pm 3.1$ & $8.3 \pm 1.2$ \\
CLE & $41.7 \pm 0.6$ & $175.8 \pm 5.5$ & $17.7 \pm 2.0$ \\
CMLE & $49.9 \pm 3.7$ & $74.2 \pm 5.5$ & $31.1 \pm 4.1$ \\
MLE & $62.6 \pm 0.8$ & $90.2 \pm 4.7$ & $132.7 \pm 10.4$ \\
HBE & $79.9 \pm 0.7$ & $196.1 \pm 12.5$ & $4.7 \pm 0.5$ \\
CBE & $31.9 \pm 1.6$ & $211.2 \pm 14.8$ & $9.5 \pm 1.2$ \\
CMBE & $31.3 \pm 0.2$ & $158.7 \pm 1.6$ & $15.6 \pm 2.1$ \\
MBE & $241.3 \pm 8.5$ & $949.5 \pm 29.7$ & $57.7 \pm 3.5$ \\
\hline
\end{tabular}

$(\mathrm{GAE}) / \mathrm{g}=$ milligram gallic acid equivalent per gram of dried extract; $(\mathrm{QE}) / \mathrm{g}=$ milligram of quercetin equivalent per gram of dried extract; (TAE)/g = milligram of tannic acid equivalent per gram of dried extract; $\mathrm{HLE}=n$-hexane extract of leaves; CLE $=$ chloroform extract of leaves; CMLE $=$ chloroform $/$ methanol extract of leaves; $\mathrm{MLE}=$ methanol extract of leaves; $\mathrm{HBE}=n$-hexane extract of bark; $\mathrm{CBE}=$ chloroform extract of bark; $\mathrm{CMBE}=$ chloroform $/$ methanol extract of bark; $\mathrm{MBE}=$ methanol extract of bark. 


\subsection{Antioxidant Activity}

All the extracts were tested to evaluate their antioxidant activity and preliminary assays indicated that the methanol extracts were more active than the others (Material not intended for publication: [17]). Antioxidant activity was measured by four spectrophotometric tests. Inhibition of lipid peroxidation was carried out by the $\beta$-carotene bleaching (BCB) assay and butylated hydroxytoluene (BHT) was used as the standard $\left(\mathrm{IC}_{50}=11.3 \pm 0.2 \mu \mathrm{g} / \mathrm{mL}\right)$. The inhibition was dose dependent (Figure 1A,B) and methanol extracts showed a moderate inhibition with an $\mathrm{IC}_{50}$ value of $197.1 \pm 14.2 \mu \mathrm{g} / \mathrm{mL}$ for MBE, whereas MLE was not able to overcome the $\mathrm{IC}_{50}$ even at the highest tested concentration. In vitro assays can be used to monitor the ability of plant extracts to quench radicals and in this study radical scavenging activity was monitored against synthetic (2,2'-azino-bis(3-ethylbenzothiazoline-6-sulfonic acid) (ABTS) radical) and physiological radicals (nitric oxide radical and superoxide anion). Methanol extracts showed a high dose-dependent ABTS scavenging activity (Figure 1A,B). At the highest concentration $(200 \mu \mathrm{g} / \mathrm{mL})$, both methanol extracts showed about $100 \%$ scavenging activity; thus, the $\mathrm{IC}_{50}$ value is needed to better understand the slight differences between the investigated vegetal parts. The $\mathrm{IC}_{50}$ calculated for the leaves and bark were $18.7 \pm 1.5$ and $15.0 \pm 0.9 \mu \mathrm{g} / \mathrm{mL}$, respectively. Trolox was used as the standard and its $\mathrm{IC}_{50}$ was $12.8 \pm 0.9 \mu \mathrm{g} / \mathrm{mL}$, evidencing the strong antioxidant potential of the extracts.

A

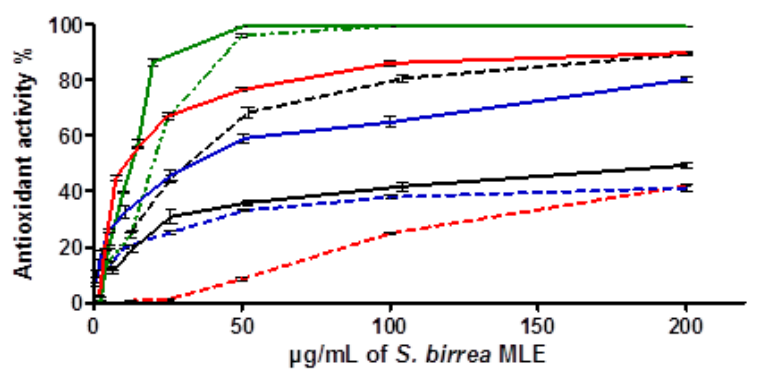

-.. ВСВ — ВНТ-ВСВ

... SO - ASCORBIC ACID-SO

-. NO - ASCORBIC ACID-NO

... ABTS - TROLOX-ABTS
B

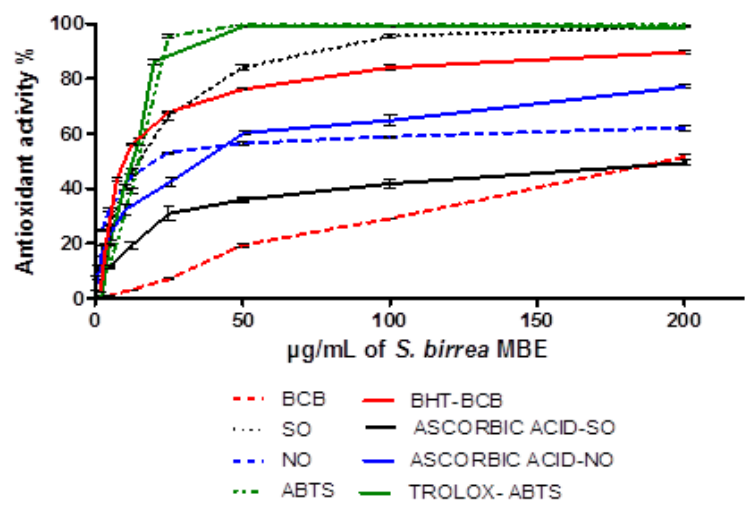

Figure 1. Antioxidant activity in vitro. Dose-dependent antioxidant activity of (A) S. birrea methanol bark extract (MBE) and (B) leaf extract (MLE) compared with the reference standards. Antioxidant activity was determined by four assays: 2,2'-azino-bis(3-ethylbenzothiazoline-6-sulfonic acid) (ABTS), $\beta$-carotene bleaching $(\mathrm{BCB})$, superoxide anion $(\mathrm{SO})$, and nitric oxide $(\mathrm{NO})$.

Both vegetal parts showed antiradical activity against the investigated physiological radicals in a dose-dependent manner (Figure 1A,B), but MBE was more able to quench both radicals than MLE. In particular, MBE showed $\mathrm{IC}_{50}$ values of $19.9 \pm 2.9$ and $15.6 \pm 1.0 \mu \mathrm{g} / \mathrm{mL}$ for nitric oxide and superoxide anion, respectively. MLE showed an $\mathrm{IC}_{50}$ value of $31.1 \pm 3.3 \mu \mathrm{g} / \mathrm{mL}$ for superoxide anion, but a low inhibition of nitric oxide reaching $39.9 \pm 0.5 \%$ inhibition at $200 \mu \mathrm{g} / \mathrm{mL}$. In both assays, ascorbic acid was used as the standard showing $\mathrm{IC}_{50}$ values of $35.6 \pm 2.4$ and $199.3 \pm 20.1 \mu \mathrm{g} / \mathrm{mL}$ for nitric oxide and superoxide anion, respectively.

\subsection{Cytotoxic Effect of Bark and Leaf Methanol Extracts}

Using the Calcein AM viability assay, the cytotoxic effects of MBE and MLE from S. birrea were tested on HepG2 and normal human dermal fibroblast cells treated with different concentrations of both extracts for $24 \mathrm{~h}$.

As indicated in Figure 2A, MBE exhibited a dose-dependent cytotoxic activity on the human cancer cell line, which was higher than MLE ( $\mathrm{IC}_{50}=180$ and $270 \mu \mathrm{g} / \mathrm{mL}$, respectively), although its activity was lower than that of the methanol extract from roots (MRE) that was previously demonstrated [12]. 
Both extracts exhibited lower toxicity towards normal cells $\left(\mathrm{IC}_{50}>400 \mu \mathrm{g} / \mathrm{mL}\right.$ ), suggesting their use as a potential anticancer agent (Figure 2B).

A

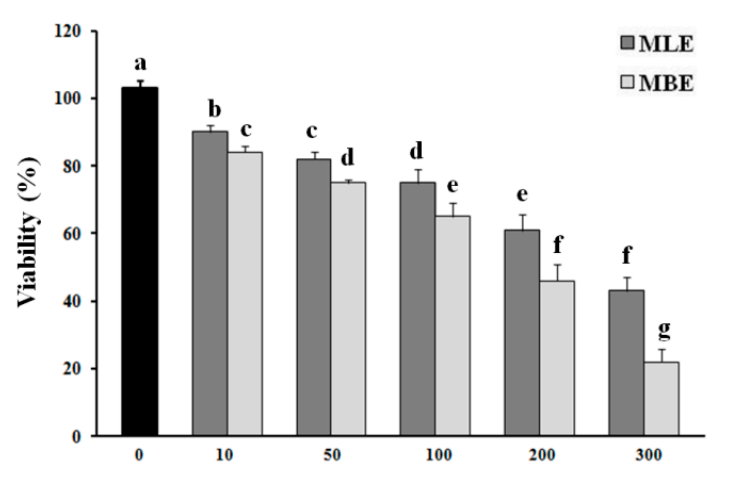

B

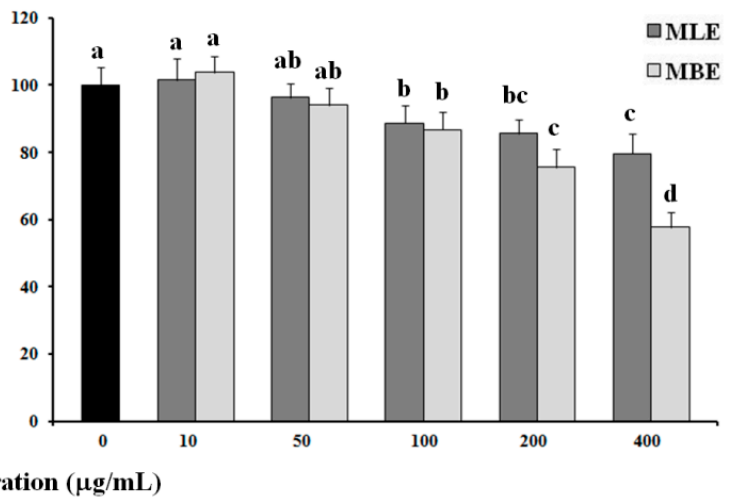

Figure 2. Cell viability assay. Cytotoxic effects of the methanol extract from leaves (MLE) and methanol extract from bark (MBE) of S. birrea on HepG2 cells (A) and human dermal fibroblasts (B). Cells were exposed to the indicated concentrations of MLE and MBE for $24 \mathrm{~h}$; cell viability was then evaluated with the Calcein AM assay as described in the Materials and Methods section. Values are the mean \pm SD of three replicates from three independent experiments. Significant differences $(p<0.05)$ are highlighted with different letters.

\subsection{Cell Morphology Analysis}

Morphological alterations of HepG2 cells treated with both extracts were observed under a phase contrast microscope. MBE-treated cells showed dose-dependent morphological alterations: many cytoplasmic vacuoles were observed, which progressively increased in number and size in proportion to the MBE concentration. Moreover, at $200 \mu \mathrm{g} / \mathrm{mL}$, the majority of cells lost their typical morphology and appeared round and translucent (Figure 3D). In the case of MLE, the effects of the treatment were much less severe: a strong vacuolization with few dead cells only at $200 \mu \mathrm{g} / \mathrm{mL}$ (Figure $3 \mathrm{H}$ ) when compared with untreated HepG2 cells (Figure 3I).

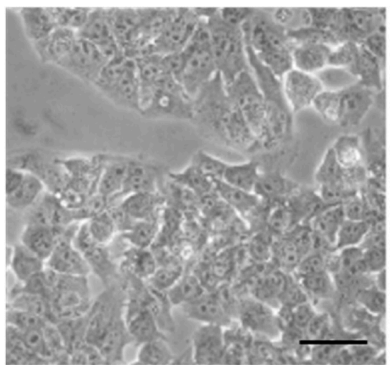

A

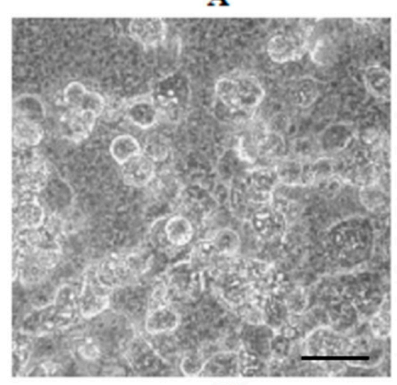

D

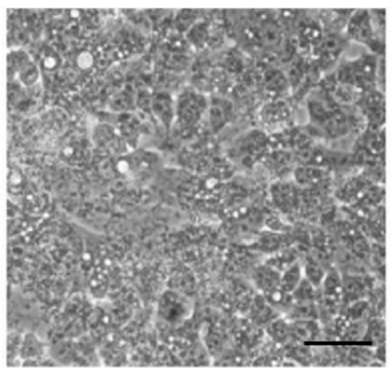

B

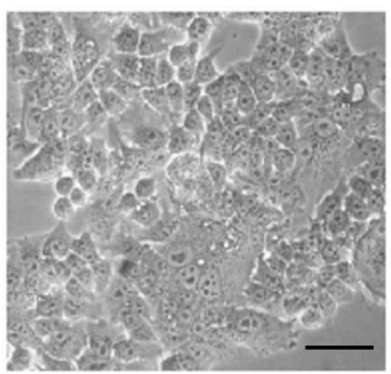

E

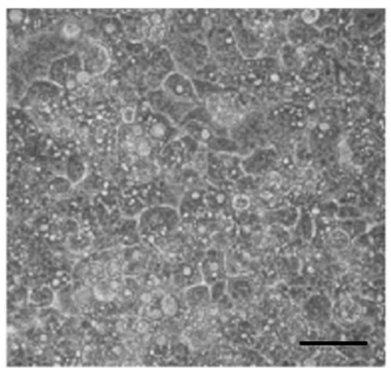

C

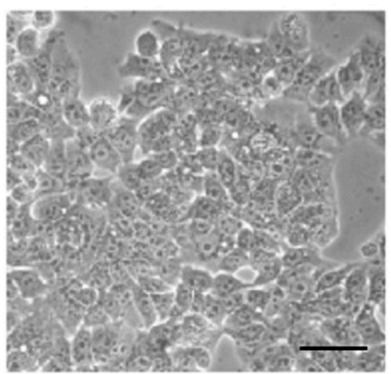

F

Figure 3. Cont. 


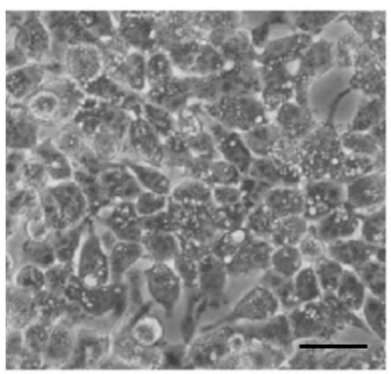

G

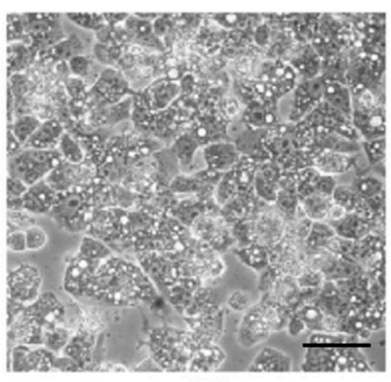

$\mathbf{H}$

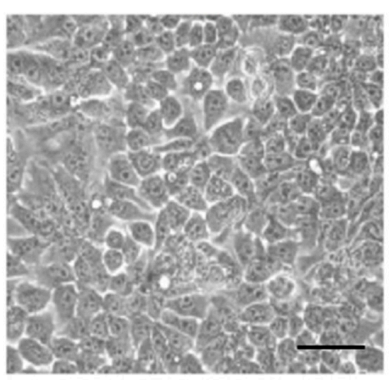

I

Figure 3. Morphological cell analysis. Inverted phase contrast images showing changes in HepG2 cells induced by leaf (MLE) and bark (MBE) methanol extracts of S. birrea. (A) $10 \mu \mathrm{g} / \mathrm{mL} \mathrm{MBE;}$ (B) $50 \mu \mathrm{g} / \mathrm{mL} \mathrm{MBE;} \mathrm{(C)} 100 \mu \mathrm{g} / \mathrm{mL}$ MBE; (D) $200 \mu \mathrm{g} / \mathrm{mL} \mathrm{MBE;} \mathrm{(E)} 10 \mu \mathrm{g} / \mathrm{mL}$ MLE; (F) $50 \mu \mathrm{g} / \mathrm{mL} \mathrm{MLE;}$

(G) $100 \mu \mathrm{g} / \mathrm{mL}$ MLE; (H) $200 \mu \mathrm{g} / \mathrm{mL}$ MLE; (I) control cells. Scale bars: $100 \mu \mathrm{m}$.

\subsection{Evaluation of Apoptosis in HepG2 Cells Treated with MLE and MBE}

The apoptotic effects of MLE and MBE were evaluated in HepG2 cells exposed to different concentrations (50, 100 and $200 \mu \mathrm{g} / \mathrm{mL}$ ) of each extract for $24 \mathrm{~h}$; cells were analyzed by flow cytometry after staining with Annexin V/7-AAD (Figure 4). Untreated cells showed a low percentage of dead cells (about 1\%), while the number of Annexin V/7-AAD-positive cells were prominent in MBE treated cells, indicating the involvement of an apoptotic process in cell death. The extract induced apoptosis in a dose-dependent manner (the percentage of apoptotic cells: $75.2 \pm 1.4 \%$, $82.0 \pm 5.3 \%$, and $89.0 \pm 7.2 \%$ at 50,100 , and $200 \mu \mathrm{g} / \mathrm{mL}$, respectively), showing a trend similar to that of MRE [12]. In contrast, MLE showed lower apoptotic activity than that of MBE and MRE: after treatment with leaf extracts, the proapoptotic rate increased to $9.5 \pm 3.1 \%, 18.2 \pm 2.3 \%$, and $38.4 \pm 4.2 \%$ in a dose-dependent manner.

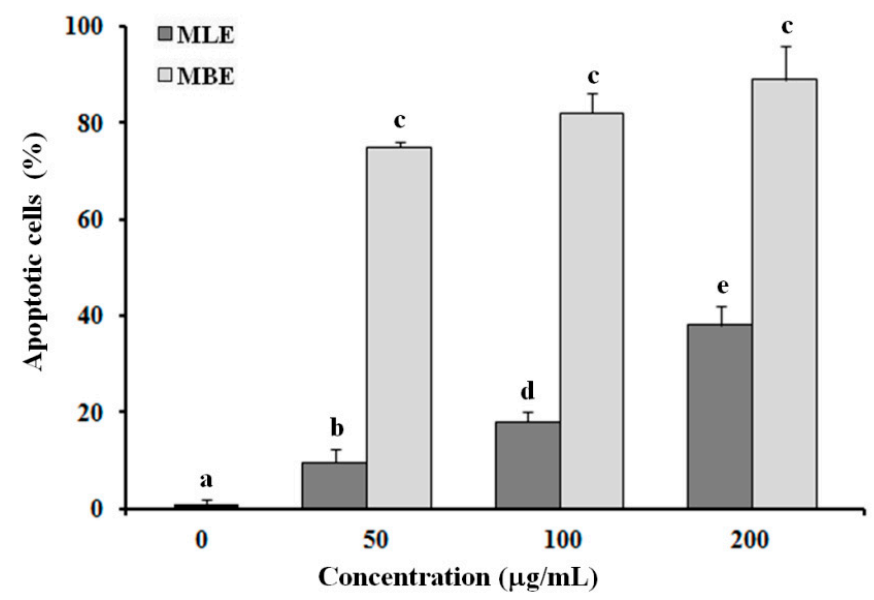

Figure 4. Quantitative evaluation of apoptosis by a flow cytometry assay. HepG2 cells were incubated for $24 \mathrm{~h}$ with 50,100, and $200 \mu \mathrm{g} / \mathrm{mL}$ of MLE or MBE and apoptosis was measured using flow cytometry after Annexin V/7-AAD double staining. Values are the mean $\pm \mathrm{SD}$ of three replicates from three independent experiments. Significant differences $(p<0.05)$ are highlighted with different letters.

\subsection{Effects of MLE and MBE on Both ROS Production and Mitochondrial Membrane Potential $\left(\Delta \Psi_{m}\right)$}

To investigate the role of ROS in extract-mediated apoptosis, we determined ROS production in HepG2 cells after $3 \mathrm{~h}$ of treatment with MLE or MBE by measuring the oxidation of a non-fluorescent probe $\left(2^{\prime}, 7^{\prime}\right.$-dichlorodihydrofluorescein diacetate (DCFH-DA)) to its reduced fluorescent form $\left(2^{\prime}, 7^{\prime}\right.$-dichlorofluorescein (DCF)). 
Figure 5 shows higher ROS levels in MBE treated cells than MLE treated cells, according to the stronger apoptotic activity of MBE.

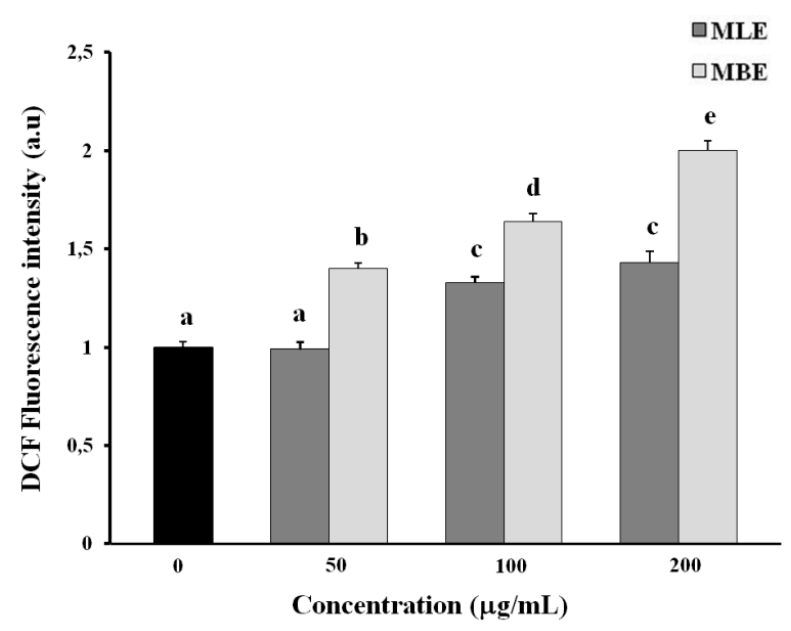

Figure 5. Quantitative evaluation of intracellular reactive oxygen species (ROS) production. HepG2 cells were incubated for $3 \mathrm{~h}$ with different concentrations (50-200 $\mu \mathrm{M})$ of extracts and intracellular ROS was determined using the peroxide-sensitive fluorescent probe $2^{\prime}, 7^{\prime}$-dichlorodihydrofluorescein diacetate (DCFH-DA) as described in the Materials and Methods section. Values are the mean \pm SD of three replicates from three independent experiments. Significant differences $(p<0.05)$ are highlighted with different letters.

Since excessive oxidative stress could lead to mitochondrial damage, causing a loss of mitochondrial membrane potential $\left(\Delta \Psi_{\mathrm{m}}\right)$ and mitochondria-mediated apoptosis, we evaluated mitochondrial membrane polarization in HepG2 cells treated for $3 \mathrm{~h}$ with different concentrations of MLE and MBE; the cationic fluorescent probe tetramethylrhodamine methyl ester (TMRM), which is easily incorporated into mitochondria of viable cells, was used. As shown in Figure 6, MBE induced a remarkable decrease in mitochondrial membrane potential $\left(\Delta \Psi_{\mathrm{m}}\right)$, leading to a decrease in TMRM fluorescence of about $50 \%$ at a concentration of $200 \mu \mathrm{g} / \mathrm{mL}$, while MLE did not alter $\Delta \Psi_{\mathrm{m}}$ significantly.

Based on these results, MBE was chosen for further investigation in subsequent experiments.

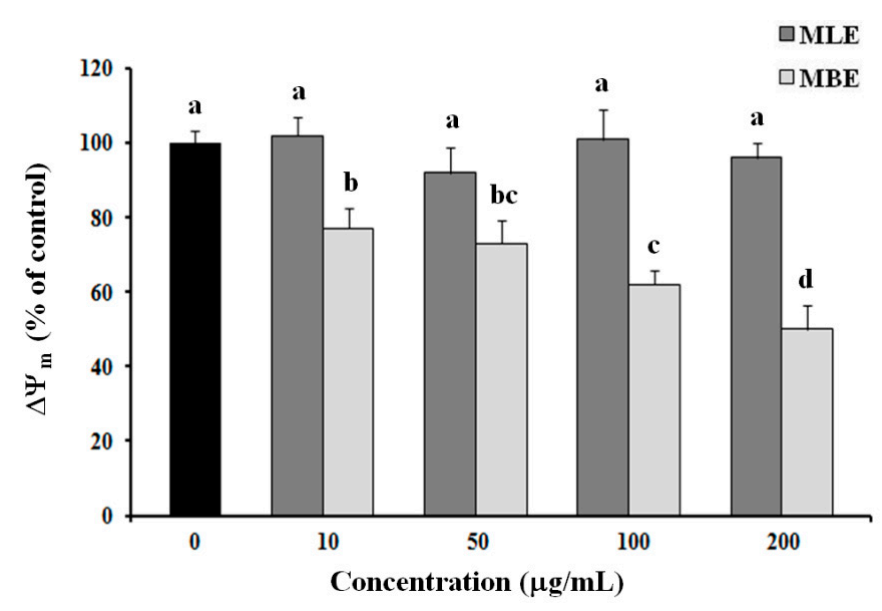

Figure 6. Measurement of mitochondrial membrane potential $\left(\Delta \Psi_{\mathrm{m}}\right)$. The integrity of mitochondrial membranes in extract-treated cells was investigated after $3 \mathrm{~h}$ of treatment by measuring tetramethylrhodamine methyl ester (TMRM) fluorescence intensity. Change in $\Delta \Psi_{\mathrm{m}}$ was determined by flow cytometry. Values are the mean \pm SD of three replicates from three independent experiments. Significant differences $(p<0.05)$ are highlighted with different letters. 


\subsection{Apoptosis Analysis by Western Blotting}

Mitochondria play a key role in apoptosis by releasing cytochrome c into the cytosol where it participates in activating caspase cascades. Therefore, we analyzed the intracellular distribution of this protein in HepG2 cells treated with $180 \mu \mathrm{g} / \mathrm{mL}$ of bark extract ( $\mathrm{IC}_{50}$ value) for 3, 6, and $24 \mathrm{~h}$. Immunoblot analysis highlights a progressive decrease in the mitochondria-enriched heavy membrane $(\mathrm{HM})$ fractions and a consequent increase in the cytosolic fractions of cytochrome c in HepG2 treated cells vs. untreated control cells (Figure 7).

Moreover, Figure 7 also shows a significant time-dependent reduction of Bcl-2 (an anti-apoptotic protein localized on the outer mitochondrial membrane) levels in HepG2 cells treated with $180 \mu \mathrm{g} / \mathrm{mL}$ of bark extract vs. untreated control cells and the activation of caspase-3, detectable by the presence of the cleaved caspase substrate poly-ADP ribose polymerase (PARP-1) after $24 \mathrm{~h}$ of treatment.

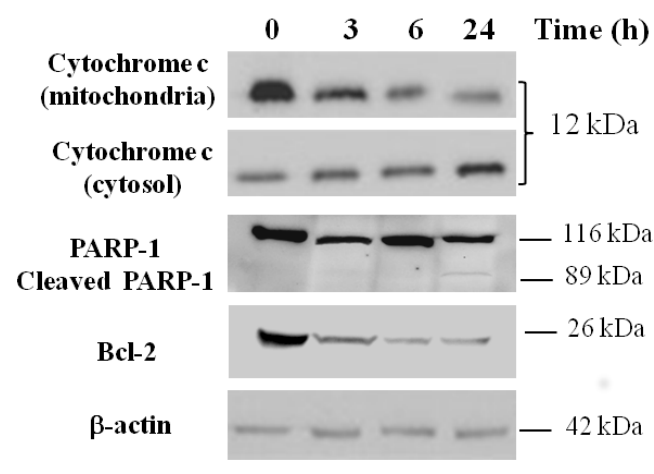

Figure 7. Western blot analysis of cytochrome c release, PARP-1 cleavage, and Bcl-2. HepG2 cells were incubated for 3,6 , and $24 \mathrm{~h}$ with $180 \mu \mathrm{g} / \mathrm{mL}\left(\mathrm{IC}_{50}\right)$ of methanol bark extract of $S$. birrea. For the detection of cytochrome c, cytosolic and mitochondrial fractions were prepared as previously described. Whole lysates were incubated with anti-PARP or anti-Bcl-2. $\beta$-actin was used as a loading control.

\section{Discussion}

Nowadays, living organisms are repeatedly exposed to several oxidizing agents (some necessary for life) and it is well known, in fact, that an increased consumption of antioxidant-rich foods and food supplements are obtained often from natural sources. Antioxidants are molecules having several chemical structures that can act as inhibitors or quenchers of free radical reactions, delaying or inhibiting cellular damage. Plant species can be considered as a rich source of antioxidant molecules. Sclerocarya birrea is used by local populations to treat several ailments, as mentioned above, and scientific evidence supporting its common use is increasing. In this study, the in vitro antioxidant activity and the cytotoxic effects of methanol extracts from bark and leaves of S. birrea were investigated.

Phenolic compounds are the major constituents of S. birrea extracts [14-16] and methanol extracts of leaves and bark are reported to have the highest content of polyphenols compared to other extracts, as showed in Table 1; in particular, MLE was found to be rich in flavonoids, whereas MBE has the highest content of tannins. As natural antioxidants, flavonoids and tannins play an important role in scavenging free radicals and preventing degenerative diseases such as cardiovascular disease [1-3]; however, they are also involved in the antiproliferation of carcinogenic cells, in cell cycle regulation, in the induction of apoptosis, and in the inhibition of platelet aggregation, and also they have antibacterial, anti-inflammatory, and antiallergic properties [18-21].

In the present study, the radical scavenging activity was performed by in vitro $\mathrm{BCB}, \mathrm{ABTS}{ }^{\bullet+}$, $\mathrm{O}_{2}{ }^{-\bullet}$, and $\mathrm{NO}^{\bullet}$ assays. Our results have shown that both of the investigated extracts (MLE and MBE) have a dose-dependent activity, similar to the reference standards (Figure 1). The comparison between the tested extracts showed that MBE has the highest radical scavenging activity than either the MLE or 
the standards (Trolox and ascorbic acid) $\left(\mathrm{ABTS}^{\bullet+}, \mathrm{O}_{2}^{-\bullet}\right.$, and $\mathrm{NO}^{\bullet}$ assays). The lipid peroxidation of both extracts by the $\beta$-carotene bleaching assay (BCB) led to a lower value than the standard (BHT). Phenolic compounds including tannins and flavonoids are known as hydrophilic antioxidants and in aqueous systems they have the highest activity. However, BCB instead provides information about the level of lipophilic compounds [22].

The cytotoxic effect of methanol extracts from S. birrea leaves and bark were tested by the Calcein AM assay. HepG2 and normal fibroblast cells were treated with different concentrations of MLE and MBE for $24 \mathrm{~h}$ and the cells' viability decreased in a dose-dependent manner. MBE had the highest cytotoxicity in HepG2 cells, whereas both extracts showed an $\mathrm{IC}_{50}$ value higher than $400 \mu \mathrm{g} / \mathrm{mL}$ in fibroblasts, demonstrating their potential anticancer effect. The higher cytotoxic activity of MBE was confirmed through more pronounced alterations in cellular morphology (Figure 3) such as vacuolization, cell detachment, and the presence round and translucent cells, which occurred at a lower concentration in bark extract than leaf extract treatment. Even in this case, the different compositions of the extracts can justify the different cellular responses to the treatments.

Cellular morphological changes can be considered as the key evidence of cytotoxicity to natural compounds or plant extracts, along with metabolic dysfunctions, alterations in proliferation rate, differentiation processes, and apoptosis. Apoptosis is a programmed cell death that plays a crucial role in embryonic development and maintenance of tissue homeostasis during adulthood by eliminating unnecessary or injured cells. Dysregulation of the apoptotic pathways results in a variety of diseases including the development and progression of some cancers [23,24]. Several studies have shown that a wide variety of plant extracts and natural substances can induce apoptosis in different tumor cells [25-28] and this occurrence can be exploited as a strategy against the progression of a tumor. The effects of MBE and MLE in inducing apoptotic processes were studied by flow cytometry and after $24 \mathrm{~h}$ of incubation, both extracts induced higher HepG2 cell death compared with untreated cells; however, bark extract treatment was more effective in inducing apoptosis in the cells, again suggesting a different effect of the various components of the extracts.

Accumulation of ROS and loss of mitochondrial membrane potential play an important role in apoptosis. ROS is physiologically generated in humans by aerobic respiration and too high a level of these species leads to oxidative stress in the cell, destroying membrane integrity and causing DNA damage. Incubation of HepG2 cells with S. birrea extracts for $3 \mathrm{~h}$ showed an increased level of ROS with both extracts, but ROS production was more pronounced when cells were treated with bark extract (Figure 5). MBE and MLE also decreased the mitochondrial membrane potential in a dose-dependent manner, particularly with MBE treatment. This loss of potential is probably due to the effect of the high levels of ROS.

Changes in mitochondrial membrane potential and mitochondrial permeability result in the release of cytochrome c from the mitochondria into the cytosol [29], a specific event in the early apoptosis mechanism. This process is blocked by Bcl-2, an anti-apoptotic protein localized on the outer mitochondrial membrane [30]. Finally, the cleaved form of the PARP-1, a physiological substrate of the activated protease caspase-3, is also considered a hallmark of apoptosis [31]. Caspase activation is a crucial process for apoptosis induction in cancer cells. Understanding the mechanism by which the anticancer drugs induce apoptosis may provide important information for proposing more effective anticancer treatments. Therefore, in order to clarify the cellular mechanisms by which bark extract of $S$. birrea induces cell death, mitochondrial apoptotic markers were analyzed by Western blot analysis. As shown in Figure 7, HepG2 cells incubated for $24 \mathrm{~h}$ with MBE showed a significant increase in cytochrome $\mathrm{c}$ release into the cytosol; the expression of the antiapoptotic protein $\mathrm{Bcl}-2$ decreased over time, and PARP-1 cleavage was activated. Thus, these hallmarks suggest that MBE cellular treatment induces cell death through an intrinsic apoptotic pathway, probably triggered by ROS generation.

Overall, considering the obtained results, the effects of cellular exposure to MBE clearly demonstrates both a higher radical scavenging activity and a greater cytotoxicity of this extract compared to MLE. This difference could be explained by the different phytochemical contents. Indeed, previous studies 
have reported the chemical composition of bark and leaf extracts using HPLC-MS analysis [14,16]. Phenolic compounds such as flavonoid glycosides (myricetin 3-O- $\alpha$-L-rhamnopyranoside, quercetin 3-O- $\beta$-D-glucopyranoside, quercetin 3-O-arabinoside, quercetin 3-O- $\alpha$-L-rhamnopyranoside, kaempferol $3-O-\alpha$-L-rhamnopyranoside) and galloylated glycosides of quercetin and kaempferol were identified mainly in leaf extracts, whereas procyanidins (condensed tannins), including epicatechin 3-O-gallate, epigallocatechin3-O-gallate, and galloylepicatechin-epigallocatechin-3-O-gallate, were found in bark extracts of S. birrea. These results agree with spectrophotometric data reported in this work, where the flavonoid content (TFC) was dominant in leaves, whereas tannins (TTC) were abundant in bark.

The classes of flavonoids and procyanidins include a wide range of molecules with several chemical structures that affect their biological activity. As previously reported [32], the degree of polymerization of procyanidins enhances their effectiveness against radical species: indeed, dimers and trimers of procyanidins were found to be more active than monomeric flavonoids. Furthermore, the antioxidant properties such as the radical-scavenging activity of flavonoids decrease proportionally to an increase in the number of glycosidic moieties and also blockage of the C-3 hydroxyl group results in a total loss of antioxidant activity [33]. Not least, the glycosylation of some flavonoids seems to decrease their antiproliferative property [34]. It was also reported that cytotoxicity increases with the degree of polymerization and the percentage of galloylation of procyanidins and the gallate group seems to interfere with crucial cell functions; the galloylation appears to be a crucial structural feature defining the activity and toxicity of phenolic mixtures [35]. The cytotoxic activity of procyanidins in different types of cancer is, finally, well documented [36-40]. Therefore, these considerations agree with the results shown in this paper, justifying both the greater in vitro antioxidant activity and the most effective antiproliferative action seen for MBE. These data are in perfect agreement with those obtained in our previous work with the S. birrea root extract in which the content of procyanidins was very high [12]. Our findings allow us to suggest their constant use as a relatively new and promising strategy to prevent cancer.

Further studies will be directed to identifying the compounds responsible of the biological activities.

\section{Materials and Methods}

\subsection{Chemicals}

Folin-Ciocalteu reagent, sodium carbonate $\left(\mathrm{Na}_{2} \mathrm{CO}_{3}\right)$, aluminum chloride $\left(\mathrm{AlCl}_{3}\right)$, sodium nitrate $\left(\mathrm{NaNO}_{3}\right)$, sodium hydroxide $(\mathrm{NaOH})$, bovine serum albumin (BSA), sodium dodecyl sulfate (SDS), triethanolamine, iron(III) chloride ( $\left.\mathrm{FeCl}_{3}\right)$, ABTS (2,2'-azino-bis(3-ethylbenzothiazoline-6-sulfonic acid)), potassium persulfate, $\beta$-carotene, linoleic acid, Tween 20, ascorbic acid, sodium nitroprusside (SNP), sulfanilamide, naphthylethylenediamine, nicotinamide adenine dinucleotide (NADH), phenazinemethosulfate (PMS), nitroblue tetrazolium (NBT), potassium phosphate monobasic $\left(\mathrm{KH}_{2} \mathrm{PO}_{4}\right)$, gallic acid, quercetin, tannic acid, 6-hydroxy-2,5,7,8-tetramethylchroman-2-carboxylic acid (Trolox), butylated hydroxytoluene (BHT), Dulbecco's Modified Eagle Medium (DMEM), dimethyl sulfoxide (DMSO), Calcein AM was purchased from Sigma Aldrich (Milan, Italy). All solvents were purchased from Carlo Erba Reagents (Milan, Italy). Trypsin-EDTA solution, FBS, glutamine, penicillin-streptomycin, and PBS were purchased from Euroclone (Milan, Italy). Tetramethylrhodamine methyl ester (TMRM, Life Technologies, Monza, Italy) was a kind gift from Massimo Lasorsa (IBBE, CNR, Bari, Italy).

\subsection{Plant Extracts}

Dried leaves and bark of Sclerocarya birrea were extracted as reported previously by Russo et al. (2013) [14] obtaining four extracts: $n$-hexane (HE), chloroform (CE), chloroform-methanol 9:1 (CME), and methanol (ME). 


\subsection{Total Content of Polyphenols, Flavonoids, and Tannins}

The total content of polyphenols (TPC), flavonoids (TFC), and tannins (TTC) were evaluated using three different spectrophotometric assays, as reported by Armentano, et al. (2015) [12]. TPC was expressed as mg gallic acid equivalent (GAE)/g of dried extract, TFC was expressed as $\mathrm{mg}$ of quercetin equivalent (QE)/g of dried extract, and TTC as mg of tannic acid equivalent (TAE)/g of dried extract.

\subsection{In Vitro Antioxidant Activity}

\subsubsection{ABTS Test}

The free radical scavenging capacity of each plant extract was studied using the 2,2'-azinobis(3-ethylbenzothiazoline-6-sulfonic acid) diammonium salt (ABTS) radical assay. Experiments were performed according to the previous report [12] with slight modifications. ABTS (7 mM) and potassium persulfate $(2.45 \mathrm{mM})$ solutions were mixed and then the mixture was allowed to stand in the dark at room temperature for $16 \mathrm{~h}$ before use in order to produce the ABTS radical (ABTS ${ }^{\bullet+}$ ). For the analysis of the extracts, the ABTS radical solution was diluted with distilled water to an absorbance of 1.00 at $734 \mathrm{~nm}$. Extracts were tested at different concentrations $(0-200 \mu \mathrm{g} / \mathrm{mL})$ and the results were expressed as the percentage of radical inhibition and then converted to $\mathrm{IC}_{50}$, which is the concentration of sample required to inhibit $50 \%$ of the ABTS radicals. Trolox was used as the reference standard.

\subsubsection{BCB Assay}

The inhibition of lipid peroxidation was monitored by the $\beta$-carotene/linoleic acid system. The assay is based on the discoloration of $\beta$-carotene, which is caused by an attack of the lipid peroxide radicals ( $\mathrm{LOO}^{\bullet}$ ) that is generated by the oxidation of linoleic acid; the addition of an effective antioxidant reduces the discoloration, which can be quantified spectrophotometrically at $470 \mathrm{~nm}$. BHT was used as a positive control and the results were expressed as the percentage of antioxidant activity (\% AA) [41].

\subsection{Nitric Oxide (NO) Scavenging Activity}

Nitric oxide scavenging activity can be estimated by using the Griess reaction. The compound sodium nitroprusside is known to decompose in aqueous solution at physiological $\mathrm{pH}$ 7.2, producing $\mathrm{NO}$, which is able to react (under aerobic conditions) with oxygen to produce stable products (nitrate and nitrite) that can be determined using the Griess reagent. Scavengers of NO compete with oxygen and leads to reduced production of nitrite ions as reported by a previous study [18]. Results were expressed as \% of inhibition.

\subsection{Superoxide Anion $\left(\mathrm{O}_{2}^{-\bullet}\right)$ Scavenging Activity}

Measurement of superoxide anion scavenging activity of $S$. birrea extracts was determined as previously reported [18]. Superoxide radicals are generated in PMS-NADH systems by oxidation of NADH and assayed by the reduction of nitroblue tetrazolium (NBT). L-Ascorbic acid was used as a control. The decreased absorbance of the reaction mixture indicates increased superoxide anion scavenging activity. Results were expressed as the percentage inhibition of superoxide anion generation and it was calculated using the following formula:

$$
\% \text { Inhibition }=\left[\left(\mathrm{A}_{0}-\mathrm{A}_{1}\right) / \mathrm{A}_{0}\right] \times 100
$$

where $A_{0}$ is the absorbance of the control and $A_{1}$ is the absorbance of the extract and standards.

\subsection{Cell Culture and Treatment with Extracts}

Human hepatoma (HepG2) and normal human dermal fibroblast (adult, HDFa, Life Technologies) cell lines were cultured and maintained under the same conditions as previously reported [12]. Bark and leaf methanol extracts (MBE and MLE, respectively) were dissolved in DMSO at the stock 
solution of $50 \mathrm{mg} / \mathrm{mL}$ and then diluted to the required concentrations. The final DMSO concentration in the cultures was no greater than $0.8 \%$ : this concentration had no effect on cell viability. DMSO-treated cells were used as controls in all the experiments. Both cell lines were treated when they were $60-70 \%$ confluent, at passages 4 to 10 (HepG2) and 4 to 8 (HDF).

\subsection{Cytotoxicity Analysis}

Leaf and bark methanol extracts of $S$. birrea were tested against HepG2 and normal human dermal fibroblast cell lines using the Calcein AM viability assay. Cells were seeded in 96-well black-walled plates $\left(1 \times 10^{4}\right.$ cells / well) and after $24 \mathrm{~h}$ were incubated with various concentrations of MBE or MLE $(10,50,100,200$, and $300 \mu \mathrm{g} / \mathrm{mL})$ at $37^{\circ} \mathrm{C}$ for $24 \mathrm{~h}$. Human fibroblasts were incubated with up to $400 \mu \mathrm{g} / \mathrm{mL}$ of MBE/MLE. Thereafter, the media were discarded from the wells and the cells were incubated with $100 \mu \mathrm{L}$ of $1 \mu \mathrm{M}$ Calcein AM in PBS for $30 \mathrm{~min}$ at $37^{\circ} \mathrm{C}$. Cellular Calcein fluorescence was detected using a plate reader (GLOMAX Multidetection System, Promega, Madison, WI, USA) at excitation and emission wavelengths of 490 and $510-570 \mathrm{~nm}$, respectively.

\subsection{Cell Imaging}

HepG2 cells were cultured in standard conditions in 24-well tissue culture plates at a seeding density of $2 \times 10^{5}$ cells/well and treated with increasing concentrations $(10,50,100$, and $200 \mu \mathrm{g} / \mathrm{mL}$ ) of MBE and MLE for $24 \mathrm{~h}$. The untreated cells served as a control. Changes in cell morphology were imaged using inverted phase contrast microscopy at $40 \times$ magnification (Nikon Eclipse TS100, Nikon, Tokyo, Japan).

\subsection{Apoptosis Assay}

The percentage of apoptotic cells was determined using the Annexin V/7-AAD double staining assay, according to the manufacturer's protocol (BD Pharmingen, San Jose, CA, USA). In brief, HepG2 cells were plated in a 12-well culture plate at a density of $2 \times 10^{5}$ cells/well and treated with MBE and MLE (50, 100, and $200 \mu \mathrm{g} / \mathrm{mL}$ ) for $24 \mathrm{~h}$. At the end of the treatment, cells were harvested and suspended in $500 \mu \mathrm{L}$ of binding buffer containing $5 \mu \mathrm{L}$ Annexin $\mathrm{V}$ and $5 \mu \mathrm{L}$ 7-AAD and then incubated in the dark for $15 \mathrm{~min}$. Finally, at least $1 \times 10^{4}$ stained cells per sample were analyzed in a BD FACSCanto II (BD Pharmingen, San Jose, CA, USA) flow cytometry analyzer.

\subsection{Reactive Oxygen Species (ROS) Measurements}

The intracellular ROS level was measured using a fluorescent probe, $2^{\prime}, 7^{\prime}$-dichlorodihydrofluorescein diacetate (DCFH-DA), as previously reported [12]. Briefly, HepG2 cells were seeded into dark 96-well tissue culture plates at a density of $5 \times 10^{4}$ cells/well and incubated for $24 \mathrm{~h}$ at $37^{\circ} \mathrm{C}$. Following treatment with MLE or MBE (50, 100, and $200 \mu \mathrm{g} / \mathrm{mL}$ ) for $3 \mathrm{~h}$, cells were stained with $10 \mu \mathrm{M}$ DCFH-DA for $30 \mathrm{~min}$ at $37^{\circ} \mathrm{C}$ in the dark. The fluorescence was measured by the GLOMAX Multidetection System (Promega, Madison, WI, USA) using a blue filter (Ex $490 \mathrm{~nm}$, Em 510-570 nm).

\subsection{Mitochondrial Membrane Potential (MMP) Evaluation}

Changes in mitochondrial membrane potential (MMP) were monitored by flow cytometry (FACSCanto II) with the mitochondrial tracking fluorescent dye TMRM. In brief, $2 \times 10^{5}$ cells were cultured in 12-well plates and treated with MLE and MBE at different concentrations (10, 50, 100, and $200 \mu \mathrm{g} / \mathrm{mL}$ ) for $3 \mathrm{~h}$. The cells were then detached, washed in ice-cold PBS, and incubated for $20 \mathrm{~min}$ at $37^{\circ} \mathrm{C}$ in darkness with $150 \mathrm{nM}$ TMRM in PBS. After dilution with PBS, cells were analyzed by FACS with an excitation wavelength of $488 \mathrm{~nm}$ and an emission wavelength of $575 \mathrm{~nm}$. 


\subsection{Western Blot Analysis}

HepG2 cells were exposed to an $\mathrm{IC}_{50}$ concentration of MBE $(180 \mu \mathrm{g} / \mathrm{mL})$ for 3, 6, and $24 \mathrm{~h}$ and then harvested and washed twice with ice-cold PBS. Mitochondria enrichment was obtained as previously described [12]. The membranes were incubated overnight at $4{ }^{\circ} \mathrm{C}$ with the specific primary antibody (anti-cytochrome c, 1:2000 Abcam). Moreover, whole lysate was blotted onto a nitrocellulose membrane and the nonspecific binding sites were blocked with TBST buffer containing $5 \%$ nonfat dry milk. The membranes were incubated with anti-PARP-1 or anti-Bcl-2, both diluted 1:200 (Santa Cruz Biotech, Dallas, TX, USA). After incubation with appropriate secondary antibodies, detection was performed using the enhanced chemiluminescence (ECL) kit (GE).

\subsection{Statistical Analysis}

All the results are presented as mean \pm SD of three independent experiments performed in triplicate. In the viability assays, the percentage survival values were normalized by an arcsine square root transformation and then compared using analysis of variance (ANOVA) and Tukey's HSD test. In the measurement of reactive oxygen species and mitochondrial membrane potential, statistical significances were analyzed by one-way analysis of variance (ANOVA) and Tukey's HSD test. Both analyses were performed using software R version 2.8.1 (R Development Core Team, Vienna, Austria, 2008). Different letters denote significant differences $(p<0.05)$.

Acknowledgments: This research was supported by the Salute di Genere and Osteopatia Masters of the University of Basilicata, Project "Monitoraggio delle acque marine costiere e profonde in Basilicata" Decreto Giunta Regionale 1490 of 4/12/2014. This work also received financial support from National Funds (FCT/MEC, Fundação para a Ciência e Tecnologia/Ministério da Educação e Ciência) through project UID/QUI/50006/2013, co-financed by European Union (FEDER under the Partnership Agreement PT2020), and from Programa de Cooperación Interreg V-A España-Portugal (POCTEP) 2014-2020 (project 0377_IBERPHENOL_6_E). To all financing sources the authors are greatly indebted.

Author Contributions: Daniela Russo and Rocchina Miglionico performed in vitro assays, analyzed the data and designed the figures. Monica Carmosino performed morphological analyses and helped in data interpretation. Faustino Bisaccia planned, supervised the work and helped in data interpretation. Paula B. Andrade and Patrícia Valentão contributed materials for experiments and participated in designing the chemical experiments. Luigi Milella and Maria Francesca Armentano designed the workflow and directed the project, wrote the paper in consultation with all co-authors that read and approved the final manuscript.

Conflicts of Interest: The authors declare no conflict of interest.

\section{References}

1. Cragg, G.M.; Newman, D.J. Natural products: A continuing source of novel drug leads. Biochim. Biophys. Acta 2013, 1830, 3670-3695. [CrossRef] [PubMed]

2. Bisio, A.; de Mieri, M.; Milella, L.; Schito, A.M.; Parricchi, A.; Russo, D.; Alfei, S.; Lapillo, M.; Tuccinardi, T.; Hamburger, M. Antibacterial and Hypoglycemic Diterpenoids from Salvia chamaedryoides. J. Nat. Prod. 2017, 80, 503-514. [CrossRef] [PubMed]

3. Milella, L.; Milazzo, S.; de Leo, M.; Vera Saltos, M.B.; Faraone, I.; Tuccinardi, T.; Lapillo, M.; de Tommasi, N.; Braca, A. $\alpha$-Glucosidase and $\alpha$-Amylase Inhibitors from Arcytophyllum thymifolium. J. Nat. Prod. 2016, 79, 2104-2112. [CrossRef] [PubMed]

4. Gerbino, A.; Schena, G.; Milano, S.; Milella, L.; Barbosa, A.F.; Armentano, F.; Procino, G.; Svelto, M.; Carmosino, M. Spilanthol from Acmella oleracea lowers the intracellular levels of cAMP impairing NKCC2 phosphorylation and water channel AQP2 membrane expression in mouse kidney. PLoS ONE 2016, 11, e0156021. [CrossRef] [PubMed]

5. Ntie-Kang, F.; Njume, L.E.; Malange, Y.I.; Günther, S.; Sippl, W.; Yong, J.N. The chemistry and biological activities of natural products from northern african plant families: From taccaceae to Zygophyllaceae. Nat. Prod. Bioprospect. 2016, 6, 63-96. [CrossRef] [PubMed]

6. Mileo, A.M.; Miccadei, S. Polyphenols as modulator of oxidative stress in cancer disease: New therapeutic strategies. Oxid. Med. Cell. Longev. 2016, 2016. [CrossRef] [PubMed] 
7. Malongane, F.; McGaw, L.; Mudau, F. The synergistic potential of various teas, herbs and therapeutic drugs in health improvement: A review. J. Sci. Food Agric. 2017, 97, 4679-4689. [CrossRef] [PubMed]

8. León-González, A.J.; Auger, C.; Schini-Kerth, V.B. Pro-oxidant activity of polyphenols and its implication on cancer chemoprevention and chemotherapy. Biochem. Pharmacol. 2015, 98, 371-380. [CrossRef] [PubMed]

9. Braca, A.; Politi, M.; Sanogo, R.; Sanou, H.; Morelli, I.; Pizza, C.; de Tommasi, N. Chemical composition and antioxidant activity of phenolic compounds from wild and cultivated Sclerocarya birrea (Anacardiaceae) leaves. J. Agric. Food Chem. 2003, 51, 6689-6695. [CrossRef] [PubMed]

10. Hamza, O.J.; van den Bout-van, C.J.; Matee, M.I.; Moshi, M.J.; Mikx, F.H.; Selemani, H.O.; Mbwambo, Z.H.; van der Ven, A.J.; Verweij, P.E. Antifungal activity of some Tanzanian plants used traditionally for the treatment of fungal infections. J. Ethnopharmacol. 2006, 108, 124-132. [CrossRef] [PubMed]

11. Mariod, A.A.; Matthäus, B.; Hussein, I.H. Antioxidant properties of methanolic extracts from different parts of Sclerocarya birrea. Int. J. Food Sci. Technol. 2008, 43, 921-926. [CrossRef]

12. Armentano, M.F.; Bisaccia, F.; Miglionico, R.; Russo, D.; Nolfi, N.; Carmosino, M.; Andrade, P.B.; Valentão, P.; Diop, M.S.; Milella, L. Antioxidant and proapoptotic activities of Sclerocarya birrea [(A. Rich.) Hochst.] methanolic root extract on the hepatocellular carcinoma cell line HepG2. BioMed Res. Int. 2015, 2015. [CrossRef] [PubMed]

13. Tanih, N.F.; Ndip, R.N. The acetone extract of Sclerocarya birrea (Anacardiaceae) possesses antiproliferative and apoptotic potential against human breast cancer cell lines (MCF-7). Sci. World J. 2013, 2013. [CrossRef] [PubMed]

14. Russo, D.; Kenny, O.; Smyth, T.J.; Milella, L.; Hossain, M.B.; Diop, M.S.; Rai, D.K.; Brunton, N.P. Profiling of phytochemicals in tissues from Sclerocarya birrea by HPLC-MS and their link with antioxidant activity. ISRN Chromatogr. 2013, 2013. [CrossRef]

15. Schulze-Kaysers, N.; Feuereisen, M.; Schieber, A. Phenolic compounds in edible species of the Anacardiaceae family-A review. RSC Adv. 2015, 5, 73301-73314. [CrossRef]

16. Jiménez-Sánchez, C.; Lozano-Sánchez, J.; Gabaldón-Hernández, J.A.; Segura-Carretero, A.; Fernández-Gutiérrez, A. RP-HPLC-ESI-QTOF/MS 2 based strategy for the comprehensive metabolite profiling of Sclerocarya birrea (marula) bark. Ind. Crops Prod. 2015, 71, 214-234. [CrossRef]

17. Milella, L. Antioxidant Activity of Different Extracts from Marula; Department of Science, University of Basilicata: Potenza, Italy, 2017.

18. Russo, D.; Valentão, P.; Andrade, P.B.; Fernandez, E.C.; Milella, L. Evaluation of antioxidant, antidiabetic and anticholinesterase activities of Smallanthus sonchifolius landraces and correlation with their phytochemical profiles. Int. J. Mol. Sci. 2015, 16, 17696-17718. [CrossRef] [PubMed]

19. Hilou, A.; Bougma, A.; Dicko, M.H. Phytochemistry and Agro-Industrial Potential of Native Oilseeds from West Africa: African Grape (Lannea microcarpa), Marula (Sclerocarya birrea), and Butter Tree (Pentadesma butyracea). Agriculture 2017, 7, 24. [CrossRef]

20. Ugartondo, V.; Mitjans, M.; Touriño, S.; Torres, J.L.; Vinardell, M.P. Comparative antioxidant and cytotoxic effect of procyanidin fractions from grape and pine. Chem. Res. Toxicol. 2007, 20, 1543-1548. [CrossRef] [PubMed]

21. Rue, E.A.; Rush, M.D.; van Breemen, R.B. Procyanidins: A comprehensive review encompassing structure elucidation via mass spectrometry. Phytochem. Rev. 2017, 1-16. [CrossRef]

22. Dekdouk, N.; Malafronte, N.; Russo, D.; Faraone, I.; de Tommasi, N.; Ameddah, S.; Severino, L.; Milella, L. Phenolic compounds from Olea europaea L. possess antioxidant activity and inhibit carbohydrate metabolizing enzymes in vitro. Evid.-Based Complement. Altern. Med. 2015, 2015. [CrossRef] [PubMed]

23. Ashkenazi, A. Targeting the extrinsic apoptotic pathway in cancer: Lessons learned and future directions. J. Clin. Investig. 2015, 125. [CrossRef] [PubMed]

24. Hassan, M.; Watari, H.; AbuAlmaaty, A.; Ohba, Y.; Sakuragi, N. Apoptosis and molecular targeting therapy in cancer. BioMed Res. Int. 2014, 2014. [CrossRef] [PubMed]

25. Srivastava, S.; Somasagara, R.R.; Hegde, M.; Nishana, M.; Tadi, S.K.; Srivastava, M.; Choudhary, B.; Raghavan, S.C. Quercetin, a natural flavonoid interacts with DNA, arrests cell cycle and causes tumor regression by activating mitochondrial pathway of apoptosis. Sci. Rep. 2016, 6. [CrossRef] [PubMed]

26. Ha, S.H.; Jin, F.; Kwak, C.H.; Abekura, F.; Park, J.Y.; Park, N.G.; Chang, Y.C.; Lee, Y.C.; Chung, T.W.; Ha, K.T. Jellyfish extract induces apoptotic cell death through the p38 pathway and cell cycle arrest in chronic myelogenous leukemia K562 cells. PeerJ 2017, 5, e2895. [CrossRef] [PubMed] 
27. Nakanishi, T.; Song, Y.; He, C.; Wang, D.; Morita, K.; Tsukada, J.; Kanazawa, T.; Yoshida, Y. Relationship between triterpenoid anticancer drug resistance, autophagy, and caspase-1 in adult T-cell leukemia. PeerJ 2016, 4, e2026. [CrossRef] [PubMed]

28. Zielińska-Przyjemska, M.; Kaczmarek, M.; Krajka-Kuźniak, V.; Łuczak, M.; Baer-Dubowska, W. The effect of resveratrol, its naturally occurring derivatives and tannic acid on the induction of cell cycle arrest and apoptosis in rat C6 and human T98G glioma cell lines. Toxicol. In Vitro 2017, 43, 69-75. [CrossRef] [PubMed]

29. Giorgio, V.; Guo, L.; Bassot, C.; Petronilli, V.; Bernardi, P. Calcium and regulation of the mitochondrial permeability transition. Cell Calcium 2017. [CrossRef] [PubMed]

30. Edlich, F.; Martinou, J.C. Bcl-2 Protein Interplay on the Outer Mitochondrial Membrane. In Mitochondria and Cell Death; Cell Death in Biology and Diseases Series; Hockenbery, D., Ed.; Humana Press: New York, NY, USA, 2013; pp. 69-83, ISBN 978-1-4939-3610-6.

31. Vizetto-Duarte, C.; Custódio, L.; Gangadhar, K.N.; Lago, J.H.G.; Dias, C.; Matos, A.M.; Neng, N.; Nogueira, J.M.F.; Barreira, L.; Albericio, F. Isololiolide, a carotenoid metabolite isolated from the brown alga Cystoseira tamariscifolia, is cytotoxic and able to induce apoptosis in hepatocarcinoma cells through caspase- 3 activation, decreased Bcl-2 levels, increased p53 expression and PARP cleavage. Phytomedicine 2016, 23, 550-557. [CrossRef] [PubMed]

32. Kumar, S.; Pandey, A.K. Chemistry and biological activities of flavonoids: An overview. Sci. World J. 2013, 2013. [CrossRef] [PubMed]

33. Massini, L.; Rico, D.; Martin-Díana, A.; Barry-Ryan, C. Study of antioxidant properties of fractionated apple peel phenolics using a multiple-assay approach. Int. Food Res. J. 2016, 23, 1996-2005.

34. Chen, J.; Teng, J.; Ma, L.; Tong, H.; Ren, B.; Wang, L.; Li, W. Flavonoids isolated from the flowers of Limonium bicolor and their in vitro antitumor evaluation. Pharmacogn. Mag. 2017, 13, 222-225. [CrossRef] [PubMed]

35. Karas, D.; Ulrichová, J.; Valentová, K. Galloylation of polyphenols alters their biological activity. Food Chem. Toxicol. 2017, 105, 223-240. [CrossRef] [PubMed]

36. Avelar, M.M.; Gouvêa, C.M. Procyanidin B2 cytotoxicity to MCF-7 human breast adenocarcinoma cells. Indian J. Pharm. Sci. 2012, 74. [CrossRef]

37. Hah, Y.S.; Kim, J.G.; Cho, H.Y.; Park, J.S.; Heo, E.P.; Yoon, T.J. Procyanidins from Vitis vinifera seeds induce apoptotic and autophagic cell death via generation of reactive oxygen species in squamous cell carcinoma cells. Oncol. Lett. 2017, 14, 1925-1932. [CrossRef] [PubMed]

38. Taparia, S.S.; Khanna, A. Procyanidin-rich extract of natural cocoa powder causes ROS-mediated caspase-3 dependent apoptosis and reduction of pro-MMP-2 in epithelial ovarian carcinoma cell lines. Biomed. Pharmacother. 2016, 83, 130-140. [CrossRef] [PubMed]

39. Actis-Goretta, L.; Romanczyk, L.J.; Rodriguez, C.A.; Kwik-Uribe, C.; Keen, C.L. Cytotoxic effects of digalloyl dimer procyanidins in human cancer cell lines. J. Nutr. Biochem. 2008, 19, 797-808. [CrossRef] [PubMed]

40. Duan, Y.; Xu, H.; Luo, X.; Zhang, H.; He, Y.; Sun, G.; Sun, X. Procyanidins from Nelumbo nucifera Gaertn. Seedpod induce autophagy mediated by reactive oxygen species generation in human hepatoma G2 cells. Biomed. Pharmacother. 2016, 79, 135-152. [CrossRef] [PubMed]

41. Mezrag, A.; Malafronte, N.; Bouheroum, M.; Travaglino, C.; Russo, D.; Milella, L.; Severino, L.; de Tommasi, N.; Braca, A.; Dal Piaz, F. Phytochemical and antioxidant activity studies on Ononis angustissima L. aerial parts: Isolation of two new flavonoids. Nat. Prod. Res. 2017, 31, 507-514. [CrossRef] [PubMed]

(C) 2018 by the authors. Licensee MDPI, Basel, Switzerland. This article is an open access article distributed under the terms and conditions of the Creative Commons Attribution (CC BY) license (http://creativecommons.org/licenses/by/4.0/). 